\title{
HERMENÊUTICA E LEITURA DA HISTÓRIA EM JOAQUIM DE FIORE
}

Noeli Dutra Rossatto*

SÍNTESE - Joaquim de Fiore exerceu grande influência entre os medievais, principalmente por sua leitura "concordista" da Bíblia e por sua interpretação da História, como uma história teológica, da qual sabia-se que haveria ainda uma terceira idade, de plenitude e perfeição.

PALAVRAS-CHAVE - Joaquim de Fiore, concordismo bíblico, história, milenarismo.
ABSTRACT - Great was the influence of Joachim de Fiore on the medieval thought, specially on account of his "concordist" interpretation of the Bible and on account of his explication of the history as a theological one, with the belief that there would be yet a third age of fullness and perfection.

KEY WORDS - Joachim de Fiore, biblical concordism, history, millenarism.

Com o presente texto se quer sugerir umá aproximação inicial a dois temas centrais da obra de Joaquim de Fiore: a hermenêutica concordista e a leitura e interpretação da história. Mais precisamente, se discute a relação entre o chamado método concordista e a leitura e interpretação dos textos bíblicos e da história no enfoque proposto por este abade calabrês que viveu na segunda metade do século XII, entre os anos 1130 e 1202. Esta temática, referente à hermenêutica e à leitura e interpretação da história, está diretamente relacionada com uma terceira, a saber, a problemática da trindade. Esta última, porém, só será tratada na medida exata em que servir para esclarecer e determinar a estrutura elementar aportada pela concepção de história, afirmada ao longo da obra de Joaquim de Fiore.

Antes, porém, de entrar no tema propriamente anunciado, faz-se algumas observações periféricas a respeito do autor, sua obra e o contexto no qual ele viveu, haja vista que estes dados viabilizam o entendimento do conteúdo filosófico de seus textos e, amiúde, elucidam a problemática em questão.

\section{1 - Joaquim de Fiore e a tradição}

A vida e a obra de Joaquim de Fiore, como também o destino de ambas na História da Filosofia Ocidental, têm um caráter um tanto quanto peculiar, o que faz

* Professor da Universidade Federal de Santa Maria - UFsM e Doutorando da Universitat de Barcelona (Espanha). 
com que estejam marcadas por um certo mistério. Isto porque, de um lado, a figura do abade calabrês, forjada ao longo da tradição, se constitui de uma mescla de pensador, profeta, guia espiritual e reformador religioso, influenciando não só diretamente 0 período em que vive, mas também os anos subseqüentes à sua obra. De outro lado, devido em parte ao radicalismo implementado por seus seguidores - algumas vezes ampliando e outras inclusive falsificando a sua doutrina se criou uma atmosfera preconceituosa que condiciona e impõe, ainda hoje, uma certa moldura interpretativa ao seu pensamento.

Apesar disso, se pode constatar que muitos especialistas ao estudarem a sua obra fazem suas as palavras escritas por Antonio Crocco, ao qualificar a Joaquim de Fiore como "la più singolare ed affascinante figura del Medioevo cristiano". Isto, curiosamente, contrasta com o enorme vazio deixado pela maioria dos manuais de História da Filosofia, no que diz respeito à obra do autor. Seu nome raramente aparece; e, nos poucos casos em que é citado, muitas vezes acaba recebendo um tratamento depreciativo e caricaturesco. ${ }^{2}$ Isto traz uma série de dificuldades de caráter bibliográfico e historiográfico, além de abrir uma irreparável lacuna que dificulta traçar um quadro fiel que retrate a vida, o pensamento, a obra e a verdadeira herança legada pelo abade calabrês ao pensamento ocidental.

Sem dúvida, Joaquim de Fiore exerceu - e ainda exerce - um enorme fascínio e sedução. Isto marca a trajetória de recepção do seu pensamento por alguns exageros e distorções interpretativas que, em contrapartida, foram moderados por algumas censuras e condenações que recairam não só sobre textos, mas também sobre muitos daqueles que pretendiam levar adiante idéias inspiradas em sua doutrina. ${ }^{3}$

\section{1 - Polêmico no século XIII}

Neste mesmo sentido, e já demonstrando o forte caráter polêmico gerado pela obra de Joaquim de Fiore, é emblemática a discussão travada durante o século XIII, alguns anos depois de sua morte, entre o chamado clero regular (ordo monachorum) e o clero secular (ordo seculorum). Os primeiros, representados pela figura do franciscano Gerardo de Borgo San Donnino, que publicara o polêmico Introdutorium in Evangelium Aeternum, em Paris, no ano de 1254, hoje desaparecido; e os outros, situados na Escola de Paris, sob a liderança de Guilherme de SaintAmour que, em reação, escreve o De Periculis Novissimorum Temporum. Esta disputa terá como resultado a condenação de ambos os dois textos, seguida da

1 CROCCO, A. Gioacchino da Fiore. La più singolare de affascinante figura del medioevo cristiano. Nápoles, Empireo, 1960, ver em especial as páginas 21-22.

2 Veja-se, por exemplo, o caso de HIRSCHBERGER, J. História da filosofia na Idade Média. S. Paulo, Herder, 1966, p. 108, que afirma ser Joaquim de Fiore um "verdadeiro louco", devido às idéias que ele defende.

3 É importante sublinhar, neste sentido, o resgate histórico da obra de Joaquim de Fiore e de sua influência ao largo da história do pensamento ocidental, feito por Henry De Lubac em seus dois volumes: La postérité spirituelle de Joaquim de Flore. tomo I: De Joachim à Schelling; tomo II: De Saint Simon à nous jour. Paris, Lethielleux, 1979. 
proibição e apreensão dos mesmos. ${ }^{4}$ Em meio a isto, tem-se ao nivel institucional a substituição do ministro geral da ordem franciscana, João de Parma - um joaquinita assumido - por São Boaventura, em $1258 .{ }^{5}$

Neste mesmo século, ainda se pode encontrar a análise realizada por Tomás de Aquino de algumas teses escatológicas joaquinitas. Este autor escolástico aponta para supostos desvios doutrinários, porém retém-se prudentemente quanto à condenação da obra de Joaquim de Fiore. ${ }^{6}$ Aliás, apesar dos diferentes inquéritos pelos quais passou a obra deste pensador no decorrer dos séculos seguintes, pesa ainda hoje sobre seus escritos a aprovação de três papas aos quais o autor submeteu seus textos. ${ }^{7}$

Disso tudo se pode concluir que, tanto o esquecimento quanto a depreciação que vitimam a obra do abade calabrês, acabam contrastando, na história do pensamento subseqüente, com a sua importância, projeção e influência no contexto medieval dos séculos XII e XIII, bem como a sua recepção e apropriação renascentista.

\section{2 - Atualidade de seu pensamento}

O matiz polêmico que aporta a obra do abade de Fiore não se restringe tão somente à Idade Média e ao Renascimento, pois que, atualmente, ela produz ainda significativas divergências entre reconhecidos estudiosos. Alguns destes especialistas apontam a Joaquim de Fiore como um heterodoxo precursor das reformas protestantes, enquanto outros refutam esta perspectiva insistindo em sua ortodoxa vinculação com a tradição católica. ${ }^{8}$ Entretanto, não cabe aqui rastrear os meandros destas desavenças teórico-interpretativas, que merecem um estudo mais aprofundado.

4 O texto de Gerardo de Borgo resulta desaparecido e, ao que tudo indica, seu autor passou o resto de seus dias na prisão eciesiástica. Cf. SARANAYANA, J. I. Joaquin de Fiore y Tomas de Aquino. Historia doctrinal de una polemica. Pamplona, EUNSA, 1979, p. 57 seg.; também, FALBEL, N. Os espirituais franciscanos. S. Paulo, Perspectiva/Fapesp/Editora da Universidade de S. Paulo, 1995, ps. $70 \mathrm{ss}$.

5 Veja-se em especial: FALBEL, N. op. cit., p. 49 a 77.

6 Confira: TOMÁS DE AQUINO. Suma teológica. vol. IV, prim. sec., quest. CVI, art. IV; e Suma teológica. vol. I, suplemento, quest. LXXVI, art. II. A respeito da polêmica entre o clero secular e o clero regular e a posição de Tomás de Aquino, veja-se: SARANYANA, J. I Joaquin de Fiore y Tomas de Aquino. ed. citada.

7 O Expositio in Apocalipsim, escrito entre os anos 1184 a 1200, recebe a autorização do papa Lúcio III, reiterada por Urbano III, em 1188; e, um pouco mais tarde, em 1188, Clemente I pede para que Fiore acabe este trabaiho. Ademais, o texto Concordia novi et veteris testamenti foi submetido pelo autor ao juizo da Cúria Romana. Confira o prefácio da recente publicação: GIOACCHINO DA FIORE. Introduzione all'Apocalisse. Prefazione e testo critico di Kurt-Victor Selge. Traduzione di Gian Luca Potesta. (Centro intemazionale de Studi gioachimiti S. Giovanni in Fiore. Opera di Gioacchino da Fiore: teste e strumenti 6), Roma, Viella, 1995.

8 Sobre a discussão a respeito da ortodoxia e hetorodoxia de Joaquim de Fiore, veja-se: FORTUNY, F. J. “¿Crisis o nuevo espíritu? 1. Joaquín de Fiore y su 'Corcordia',” in. Acta mediaevalia - historica et archaeologica, n. 16-17, Barcelona, Universitat de Barcelona, 1995-96, p. 86 seg. Ainda: MOTTU, H. La manifestazione dello spirito secondo Gioacchino da Fiore. Ermeneutica e teologia della historia secondo il "Trattato sui quatto Vangeli", trad. italiana de Roberto Ussegiio. Casa Editore Marietti, 1983, p. 23-31; e o texto consagrado a esta temática de REEVES, M. The influence of Prophecy in the Later Middle Ages. A study in Joachimism. Notre Dame/London, University of Notre Dame, 1993. 
O que se quer destacar é que, em meio a este contraste marcado pela defesa, adoção ou rejeição do pensamento de Fiore, por ortodoxos ou heterodoxos, carregados quase sempre de proselitismos e fanatismos, muitos elementos próprios à sua doutrina quase que subterraneamente sobrevivem na cultura ocidental. Dentre eles, destacam-se: a visão de Cristo como centro da história, ${ }^{9}$ a idéia de um movimento trinitário na história (como é o caso da dialética de Hegel e Karl Marx ou da divisão comptiana em três estados) ${ }^{10}$ e a própria idéia de um gnosticismo em política no século XX, como quer Eric Voegelin. ${ }^{11}$ Outros, mais recentemente, insistem nas possiveis influências que Joaquim de Fiore e o joaquinismo tiveram no processo de colonização da América portuguesa ou espanhola, seja na origem e desenvolvimento das populares festas do divino Espírito Santo de tradição portuguesa; ${ }^{12}$ seja nas manifestações teóricas ou posições políticas a favor dos indígenas por parte de alguns clérigos espanhóis; ou ainda, a presença de suas idẻias no desenrolar de alguns movimentos de cunho social anti-colonialista. ${ }^{13}$

Também se costuma atribuir a Joaquïm de Fiore - é o caso do francês Henri De Lubac, por exemplo - a introdução de uma forte e decisiva idéia de progresso na história. Isto porque a partir da defesa de uma Era do Espírito, se sobressai uma concepção de progresso súbito, fatal e irreversível que se contrapõe diretamente à noção de destino presente no paganismo e, em alguns casos, na própria antigüidade cristã. Pode-se afirmar, juntamente com este comentador de obra de Fiore, que, com ele, se inaugura um modelo teórico-interpretativo que afluirá no Renas-

9 Cf. RATZINGER, J. La théologie de l'histoire de Saint Bonaventure. Trad. francesa de Roberto Givord. Paris, Presses Universitaire de France, 1988, p. 17 seg.; também se pode ler a respeito na introdução, por Luiz Alberto De Boni, de BOAVENTURA. Obras escolhidas. Porto Alegre, EST/SULINA/UCS, 1983.

10 Confira, por exemplo, o que destaca CONN, N. En pos del milenio. Revolucionarios milenaristas y anarquistas místicos de la Edad Media. Trad. castelhana de R. Alaix Busquets. Barcelona, Barral Editores, 1972, p. 116: "A largo plazo, la influencia indirecta de las especulaciones de Joaquin de Fiore puede detectarse hasta el presente, sobre todo em ciertas 'filosofias de la historia' que la Iglesia desaprueba enérgicamente. Aunque el recatado mistico se hubiera horrorizado de haberlo sabido, es innegable que la fantasia joaquinista de las tres edades reapareció, por ejemplo, en las teorias de la evolución histórica expuestas por los filósofos idealistas alemanes - Lessing, Scheling, Fichte y en cierta medida por Hegel; en la idea de Augusto Comte sobre la historia como un ascenso de lo teológico, a través de la metafisica, y la fase científica; y también en la dialéctica marxista de las tres etapas del comunismo primitivo, la sociedad de clases y el comunismo final que ha de ser el reino de la libertad y en el que desaparecerá el Estado."

11 Cf. VOEGELIN, E. Science, politics and gnosticism. Washington, Regnery Gateway, 1990 e Los movimientos gnosticos como sucedáneos de la religión. Madrid: Rialp, 1966.

12 Veja-se o recente e sugestivo artigo de LUPI, J. "As festas do divino Espírito Santo", in. Anais do Congresso de História e Geografia de Santa Catarina. (4 a 7 de setembro de 1996). Florianópolis, Instituto Histórico e Geográfico de Santa Catarina, 1997, p. 747-784.

13 Ver a respeito: DE LUBAC, H. op. cit. tomo I, p. 194 seg., remete a uma bibliografia específica a respeito da relação entre a conquista da América e o joaquinismo ou a presença de correntes joaquinitas na América. Também fala sobre alguns franciscanos joaquinitas que foram ao México e Venezuela e pensavam em implementar uma nova igreja a partir dos indigenas. Ainda: SARANAYANA, J. I. "Análisis doctrinal del 'Tratado del Apocalypsi' de Gregorio Lópes (1596, en México), publicado en Madrid en 1678" in. Storia e figure dell'Apocalisse fra'500 e'600. (Atti del 4e Congresso internazionale di studi gioachimiti, San Giovanni in Fiore - 14-17 settembre 1994 - Estratto - a cura di Roberto Rusconi). Viella, 1996, p. 225 a 240. 
cimento e desembocará inevitavelmente na Modernidade. ${ }^{14}$ Em suma, parece significativo o que Henri Lefebvre detecta e sublinha em relação ao joaquinismo, ao caracterizá-lo como uma corrente mais profunda e mais escondida que o próprio agostinismo, devido ao seu conteúdo notadamente herético. ${ }^{15}$

Estudos atuais, outrossim, sobrelevam a importância de Joaquim de Fiore na medida em que o situam como um ponto de convergência da tradiçãa gnóstica cristã, através, inicialmente, de seus seguidores franciscanos e mais tarde em sua expressão marcante e visivel nos chamados gnosticismos políticos do século XX. Nesta perspectiva, os movimentos gnósticos são analisados como sucedâneos da religião, originando-se a partir da confluência de algumas características distintivas, tais como: o descontentamento dos indivíduos com a sua situação vivida; a firme fé de que os males do mundo são devidos à má organização do mesmo; a necessidade de mudar o rumo da existência humana no decorrer mesmo do processo histórico e a crença no poder humano de efetuar esta mudança. ${ }^{16}$ Cabe ao gnóstico, por fim, investigar a fórmula concreta para efetuar esta mudança. E estas características básicas estão contidas de modo bastante evidenciado na obra do abade calabrês.

Como se pode notar, ainda paira sobre a obra de Joaquim de Fiore elementos dos mais variados e distintos matizes e, por conseguinte, resta muito a fazer para que se tenha uma compreensão um pouco mais ajustada ao que realmente propôs este original pensador do final do século XII.

No que se segue, faz-se uma pequena incursão em sua obra, pondo em evidência dois temas paradigmáticos: o método concordista, que estrutura em traços gerais sua interpretação da história e a problemática referente à sua inédita leitura da história.

\section{2 - A relação entre o método concordista e a hermenêutica da histónia}

\section{1 - Aspectos formais do método concordista}

O método concordista, que veicula implícita ou explicitamente uma hermenêutica da história em Joaquim de Fiore, é elaborado a partir de uma distinta apreensão da matriz exegética tradicional. Alguns especialistas, tais como Ernesto Buonaiuti, Henri De Lubac e Henry Mottu insistem na idéia de que o método exegético, tal como vinha sendo concebido e aplicado pela leitura bíblica patristica e medieval, sofre uma mudança "substancial" nas mãos de Joaquim de Fio-

14 Diz a respeito DE LUBAC, H. op. cit. t. II, p. 347: "L'histoire est un drame, dont la Révèlation du Christ n'a fait qu'accentuer le caractère. Elle le restera jusqu'à la fin de ce monde, ou, comme on disait au temps des origines chrétiennes, de cet 'éon'. Or, avec son annonce d'un 'âge de l'Esprit', Joachim de Flore faisait pénétrer dans les esprits l'idée d'un progrès subit, fatal, irréversible, dû au passage d'une ère à l'autre à l'intérieur même du temps, - c'est-à-dire l'equivalente de ce que serait, au sens moderne du mot, 'révolution'," (grifo nosso). Ver também, MOTTU, H. op. cit., principaimente a conclusão: " $L$ 'era teologica della rivoluzione". Id. ibid. tomo I, p. 30.

16 Cf. VOEGELIN, E. Los movimientos gnósticos como sucedáneos de la religión. ed. cit. p. 66 seg.; também SARANYANA, J. I. op. cit. p. 15-23. 
re. ${ }^{17}$ Entretanto, é preciso notar que o método implementado por Fiore, à primeira vista, não se separa dos aportes básicos fomentados pela tradição exegética em seus traços fundamentais. A idéia de relacionar o Antigo com o Novo Testamento, onde este último já está prefigurado no primeiro, não apresenta nada de novo. Também a busca de um entendimento do texto bíblico através de uma divisão por períodos 'tempora ou aetates de três ou sete partes), por si só, não implica alguma mudança. Tampouco é nova a sua mentalidade simbólica, tão difícil de seguir, na aplicação de seu concordismo entre os dois testamentos.

Em que reside, então, a novidade trazida pelo método elaborado por Joaquim de Fiore? Onde está posta a originalidade deste pensador do século XII que tanto inquietou e apaixonou os séculos seguintes?

A novidade reside justamente naquilo que Joaquim de Fiore se propõe a praticar em seu método concordista. Quer uma concordia que se distingue claramente do que se entendia comumente por alegoria, apesar de não recusar totalmente este recurso exegético que, segundo ele observa, enriquece e matiza a interpretação bíblica. ${ }^{18}$ Professa uma concordia definida segundo parâmetros que se fundam na estrita literalidade dos textos bíblicos e que se orienta em conformidade com um complexo diagrama numérico e geométrico. ${ }^{19}$ Conforme expressa nosso abade:

"Concordia proprie dicimus similitudinem eque proporcionis novi et veteris Testamenti. E que dicimus quoad numerum, non quoad dignitatem: videlicet persona et persona, ordo et ordo, bellum et bellum, ex parilitate quadam, mutuis se vultis intuentibus: utpote Abram et Zacarias, Sara et Elisabeth, Isaac et Joannes Baptista et homo Jesus et Jacob, duodecim Patriarche et numeri eiusdem Apostoli. "20

Por ora, é necessário reter apenas dois pontos principais das palavras de Fiore. Primeiro, que se trata de um tipo de similitude que implica uma igualdade de proporções (similitudinem e que proporcionis) entre os dois testamentos. E, em segundo lugar, que estas proporções não são definidas pelo critério de dignidade (dignitatem), mas por uma igualdade numérica (e que decimus quoad numerum). Deste modo, se pode dizer que o conhecimento das escrituras, segundo a proposta metodológica de Joaquim de Fiore, segue um caminho que joga, de um lado, com

17 Cf. DE LUBAC, H. Exégèse médiévale. Les quatre sens de l'écriture. Seconde parte. Paris, Aubier, 1961, p. 459. Ver especificamente o primeiro capitulo que traz por título, "La teoria del sistema ermeneutico", de MOTTU, H. op. cit., p. 69 a 110.

18 GIOACHINO DA FIORE. Concordia novi et veteris testamenti. Venecia, 1527, f. 8r: "Allegoria est similitudo cuiuscumque rei parve ad maximam, ac si dies ad annum, hebdomada ad etatem, persona ad ordinem vel ad urbem, ad gentem, ad populum, et mille talia." Cf. a respeito da distinção entre alegoria e concórdia em Joaquim de Fiore: FORTUNY, F.J. “¿Crisis o nuevo espiritu? Joaquin de Fiore y su 'Concordia'," in. op. cit. p. 88 seg.; DE LUBAC, H. Exégèse médiévale. op. cit.

Comenta a respeito WEST, C.D. y ZIMDARS-SWARTZ, S. Joaquín de Fiore. Una visión espiritual de la historia. Trad. por Federico Patan. México, Fundo de Cultura Económica, 1990, p. 28: "Gran parte de la visión de Joaquin se centra en el simbolismo numérico, que desde los primeros tiempos fue considerado una clave importante para desentrañarlos secretos cósmicos. Los números son una vía para que la mente perciba la realidad según existe en el tiempo y en el espacio." REEVES, M. and HIRSCH-REICH, B. The Figurae of Joachim of Fiore. Oxford, At the Clarendon Press, 1972, p. 172, ao comentarem as figuras joaquinitas, observam que há uma perfeita regularidade geométrica na forma das mesmas (perfectly regular geometric form).

GIOACHINO DA FIORE. Concordia... ed. cit., f. 7r-7v. 
elementos numéricos pinçados dos textos bíblicos (12 patriarcas e 12 apóstolos, entre outros); e, de outro, com determinadas semelhanças de estruturas resultantes da concordância entre figuras individuais ou contextos paradigmáticos dentro de um complexo organograma histórico (por exemplo: guerra-guerra, ordemordem, perseguição-perseguição, império-império, etc.).

Aqui devem ser especificados dois passos distintos do método concordista. O primeiro, mencionado acima, está diretamente relacionado com uma concordância literal entre os dois testamentos. É preciso que concordem entre si os indivíduos, as estruturas históricas e as cifras numéricas. $\mathrm{O}$ segundo momento, que é resultado da sintese destes elementos de ordem matemática e de natureza histórica entrelaçados, é que se chama propriamente de inteligência espiritual (spiritualis intellectus). Nesta etapa do método, os fechados e obscuros conteúdos advindos do âmbito histórico e os cifrados indicativos numéricos são lidos dentro de um plano mais elevado, revelando seu verdadeiro significado. Desta leitura, que trança elementos qualitativos e quantitativos, é que resulta a chamada intelecção espiritual (spiritualis intellectus). ${ }^{21}$ Deste modo, com os dados trazidos pelos dois testamentos e com o auxílio do método concordista se pode ler e desvendar o plano global da história e, inclusive, delinear a sua tendência futura. Aqui, todos os mistérios até então velados são, enfim, desvelados ou revelados como resultados de uma operação intelectual que transpassa a sucessão temporal dos "fatos" históricos. Porém, só se consegue ultrapassar a materialidade imediata trazida pelo texto bíblico ou pelos fatos relatados nas escrituras, através de uma engenhosa leitura que harmoniza os mesmos com o auxílio de uma correspondëncia matemática. A partir disso se entende o que quer expressar Joaquim de Fiore ao dizer de modo conotativo que a manifestação pura da verdade brota do "ventre da letra" e da "casa" do Novo Testamento: "apparebit veritas manifesta procedens de ventre litterae et domo novi testamenti [...]". ${ }^{22}$ Neste mesmo sentido dirá conclusivamente Henry Mottu que [...] in fondo la 'concordia' è, per Gioacchino, un metodo che gli consente di estrapolare progressivamente un futuro, le cui linee portanti, egli crede, si trovano tutte potenzialmente nel testo scritturistico." 23

É importante notar que tudo está posto in nuce nos textos da Escritura e somente a partir de uma concordia litterae, alicerçada na letra dos mesmos, é que se pode passar para um nivel cognitivo mais elevado que é próprio à compreensão ou inteligência espiritual. Não se trata, portanto, de uma adivinhação, previsão mágica ou visionária do futuro; tampouco, de uma leitura da história que não se ampare em estritos e claros critérios formais. Aos poucos e evolutivamente passa-se de um sentido estritamente histórico (verba historica) a um sentido místico (verba mistica) - ainda guiado por figuras e enigmas - e deste, por fim, a uma compreensão espiritual:

21 Conforme observa DE LUBAC, H. Exégèse médiévale. op. cit. p. 438: “L'Écriture, dit-il(Fiore), contiene des 'verba mystica'; il est possible de les expliquer d'abord en surface, en montrant que l'histoire; mais ensuite il faut les ouvrir, pour montrer l'esprit qui s'y trouve caché"(grifos de De Lubac). GIOACCHINO DA FIORE. Concordia... ed. cit. f., 101. Ver comentários em DE LUBAC, H. Exégèse médiévale. ed. cit. p. 46 ss.

23 MOTTU, H. op. cit. p. 108. 
"Sane in futuro non solum verbs histcrice; et que terram sapere videntur, deficient, verum etiam et verba mistica, que pe? liguras et enigmata prudentibus ingeruntur, cessabunt, quia non iam per figuras aliquas, sed in spintu dei nostri faciem videbimus conditoris, similes eidem effecti, dicente Iohanne: 'Scimus quia, cum apparuerit, similes ei erimus, quia videbimus eum sicuti est'(1 Jo 3,2). "24

Deste modo, o método concordista implementado por Joaquim de Fiore alcança, de um lado, um rigor que se fundamenta nos dados históricos concretos, trazidos pelo relato escriturístico (fons litterae) ou simplesmente pela história pósescriturística, e em um planificado esquema matemático; ${ }^{25}$ de outro, isto permite que se alcance uma inteligência plena da história humana, onde se supera a fase na qual a verdade aparece selada sob a letra do texto bíblico ou mediada por um sistema de códigos ou figuras: agora, a verdade pode ser lida em plena luz. Chega-se, enfim, a uma gnose perfeita, onde se efetiva aquilo que estava anunciado pelas palavras da Primeira Epístola de São João: que Deus se manifestará e seremos semelhantes a Ele, porque veremos como Ele é.

Cabe perguntar aqui: que novidade traz esta proposta hermenêutica quando aplicada à leitura e interpretação da história?

\section{2 - A leitura da história: um prazo a mais para a aventura humana}

Em primeiro lugar, cabe observar que estes três niveis de conhecimento da história estão em direta correspondência com a pressuposição joaquinita de que a história humana se efetiva em três fases. Isto quer dizer mais exatamente que, para Joaquim, a história transcorre em acordo com três estágios bem definidos e distintos. Uma era que corresponde ao Pai, relativa ao período bíblico do Antigo Testamento, na qual os homens vivem segundo a carne (in quo vivebant homines secundum camem) e a literalidade da letra da lei, que se impõe e que deve ser forçosamente seguida. Um segundo período próprio ao Filho, que está em plena correspondência com a mescla entre carne e espírito (inter carnem et spiritum) e que diz respeito ao amor e à instauração da igreja no mundo. E um terceiro e último período que se relaciona com o Espírito Santo (in quo vivitur secundum spiritum), no qual não haverá coação externa e, conseqüentemente, a Humanidade passará a viver no reino da plena liberdade, na perfeição do entendimento e no amor.

Entre as várias formulações que apontam para este mesmo modelo de divisão da história se pode ler a seguinte, extraída do Expositio in Apocalipsim, onde Joaquim pretende esclarecer o tema dos três estados do mundo (de tribus statibus mundi):

24 GIOACCHINO DA FIORE. Introduzione all'Apocalisse. op. cit. p. 28.

25

A respeito deste aspecto do método concordista de Joaquim de Fiore, DE LUBAC, H. Exégèse médiévale. op. cit., p. 446, observa que existem regras objetivas e válidas para todos e que, "Joachim les expose méthodiquement. Si, à leur sujet, sa pensée demeure obscure, ce n'est pas que les lignes de la théorie qu'il construit soient incertaines: elles sont au contraire d'une précision compliquée, tel un mécanisme d'horlogerie aux rouages minutieusement agencés". Ou, como bem expressa MOTTU, H. op. "cit. p. 109: "[...] Gioacchino viene considerato como un exegeta calcolatore, che aveva ricercato una specie di evidenza matematica suscettibile di provare la coerenza, la 'concordanza' dei tempi della salvezza". 
"Primus trium statuum de quibus nobis sermo fuit sub tempore legis, quando populus domini adhuc pro tempore parvulus seiviens erat sub elementis huius mundi, non valens adipisci libertatem spiritus, quousque veniret ille qui ait: 'Si Filius vos liberaverit, vere liben eritis'(Jo, 8,36). Secundus status fuit sub Evangelio et manet usque nunc, in libertate quidem respectu preterit, sed non in libertate respectu futuri. [... J Tertius ergo status erit circa finem saeculi, iam non sub velamine litterae, sed in plena spiritus libertae." 26

Esta divisão da história firmada por Joaquim de Fiore demonstra uma estrita relação com a sua exegese concordista. O primeiro estado transcorre sob a égide da letra da lei, até que o Filho, num segundo momento, vem libertar deste jugo inicial. Comparado com o primeiro estado, o segundo vive um tempo de maior liberdade; porém, a verdadeira e plena liberdade somente se alcançará no terceiro estado. Neste, não se vive mais sob o véu da palavra (velamine litterae), mas na plena liberdade do espirito (plena spiritus libertae).

Por outro lado, esta divisão triádica é uma reprodução do esquema trinitário no âmbito da história. Cada uma das pessoas que compõe a trindade se encarna num período da história humana e este periodo se efetivará em pleno acordo com as características (propriedades e atributos) de cada uma das três figuras.

No que diz respeito à discussão que engloba mais especificamente a relação entre a concepção de trindade com a teoria da história, é importante destacar que, entre os comentadores mais reconhecidos da obra do calabrês, existem divergências significativas. Apesar disso, parece pacífico que a maioria deles reconhece que um dos pontos capitais da obra de Joaquim de Fiore situa-se na confluência destes dois temas. Entretanto, o desacordo nasce das diferentes interpretações decorrentes da relação entre trindade e história, o que faz com que algumas interrogações permaneçam ainda em aberto. Por exemplo, como quer Raoul Manselli: será que é a teologia trinitária que determina toda a meditação histórica em Fiore? Ou será, ao contrário, como quer Ernesto Buonaiuti, juntamente com Leone Tondelli, a escatologia que condiciona a teologia da história? Pode-se, ainda, afirmar com Marjorie Reeves que a essência da trindade não pode ser concebida em Joaquim como algo separado de sua interpretação da história. ${ }^{27} \mathrm{O}$ certo é que a relação entre estes dois temas, por si só inocentes, resultará numa teoria da história notadamente desestabilizadora do habitual modus vivendi da cultura cristã.

Outro aspecto que cabe destacar é que a teoria da história posta por Joaquim de Fiore demarca uma significativa ruptura em relação à concepção de história de proveniência agostiniana, que divide o tempo em sete partes e põe Cristo e o Espirito Santo como manifestos na sexta idade e a sétima época se dará num

26 GIOACCHINO DA FIORE. Expositio in Apocalipsim. Venecia, 1527, Liber introductorius, cap. 5, f. $5 \mathrm{v}$.

27 Cf. DE LUBAC, H. La postérité spirituelle de Joachim de Flore. ed. cit. tomo I, p. 74-5. Neste sentido observa REEVES, M. The influence of prophecy in the Later Middle Ages. A study in joaquimism. London, University of Notre Dame, 1993, p. 61-2: “Joaquim's Trinitariam doctrine, condemned in 1215, was the basis of his phylosophy of history, but, taken alone, it constituted only one migth call technical heresy. Joachim's phylosophy of history, it was now realized, constituted an incitament to subversive thought and action that was dangerously infections. It is always biliefs which provid a basis for action that must wathched". 
além-mundo ${ }^{28}$ Segundo a tradição agostiniana, a sexta época marca o término da história e o sétimo período configura a paz eterna da outra vida, não mais subordinada à temporalidade. De acordo com este esquema traçado pelo bispo de Hipona, Cristo fica posto no final dos tempos, junto com o Espirito Santo, e não há mais nada a esperar em termos de revelação divina, a não ser o fatídico final dos tempos. Neste particular, Joaquim de Fiore provoca duas mudanças fundamentais. Primeiro, ao pressupor uma radical separação entre o Antigo e o Novo Testamento, entende o tempo de Cristo como começo de um novo tempo e não como final dos tempos como queria Agostinho e a tradição cristã. $\mathrm{E}$, ademais e em segundo lugar, com a idéia de uma terceira época histórica, passa a visualizar um outro tempo, uma outra etapa que está para começar e que supera, em definitivo, a era de Cristo. ${ }^{29}$

Num plano amplo, Joaquim divide a história em três partes, sendo que todas elas se efetivam neste mundo, e, num plano interno a cada esfera, credita sete partes a cada uma delas até chegarem ao seu término. Em certo sentido, aquilo que era entendido após Agostinho como todo o movimento da história, fica subsumido em Fiore a apenas o movimento interno de cada uma das eras. Porém, isto não pode ser entendido linearmente, de modo a conceber que as épocas se sucedem mecanicamente uma após o término da outra. O esquema proposto por Joaquim é bem mais complexo. Cada era compõe-se de um círculo. Assim, se tem três círculos e cada um corresponde a uma pessoa da trindade. Entretanto, estes três círculos estão entrelaçados. ${ }^{30}$ Um novo período não começa sem que tenha acabado o outro.

Como, na época em que viveu Fiore, já se estavam cumprindo as duas primeiras etapas referentes ao Pai e ao Filho, ele passa a antever uma terceira que iniciaria aproximadamente no ano 1260 , onde o mundo alcançaria a perfeição no Espírito, através de uma religião e cultura superiores e de uma democracia comunal. ${ }^{31}$ Esta terceira era estava destinada a superar as duas anteriores. Neste periodo, reinaria a liberdade plena e o mundo seria governado por uma "grande ordem contemplativa". ${ }^{32}$ Seria inaugurado um periodo de plena espiritualidade, sabedoria, paz e amizade e as coerções externas provenientes de estruturas religiosas ou políticas tornar-se-iam obsoletas e desnecessárias numa sociedade nova regulada pelo espírito.

28 Em Agostinho o tema sobre as idades do mundo está tratado particularmente em: De civitate dei, cap. XX, livro 30; De cathechizandis rudibus, parte XXI, Genesi contra manichaeos, 1,23. Veja-se ainda sobre a comparação entre Agostinho e Joaquim de Fiore em CROCCO, A. "Il superamento del dualismo agostiniano nella concezione della storia di Gioacchimo da Fiore", in. CROCCO, A. (editor) y VV.AA. Atti del $\Pi^{\circ}$ Congresso intemazionale di studi gioacchimiti. Luzzi-Celico, 6-9 settembre 1984. Fiore, Centro di Studi Gioacchimiti, 1986, p. 114.

Cf. RATZINGER, J. op. cit. p. $20 \mathrm{~s}$.

30 Confira a famosa figura que corresponde aos três círculos trinitários em REEVES, M. and HIRSCHREICH, B. The Figurae of Joachim of Fiore. figura 26. Esta mesma figura também aparece no Expositio in Apocalipsim, ed. cit. p. 38.

31 Conforme COLETTI, T. Naming the rose. ECO, medieval signs, and modern theory. London, Cornell Univ., 1990, p. 88: "The new Age of de Spirit, as Joachim called it, was to be distinguished by a superior religion and culture and by a democratized communal monasticism in society."

Ver DE LUBAC, H. op. cit. t. II, p. 438. 
Tal compreensão é que autoriza a Joaquim de Fiore, e posteriormente seus seguidores, a pregar e buscar formas de vida referentes a esta terceira fase da história, como também a questionar aqueles que não se conformavam ao que estava demarcado como sendo próprio a este estágio.

A partir do abade Fiore, pode-se dizer que um outro tipo de esperança invade o pensamento cristão medieval após a virada do primeiro milênio, plasmando a idéia de que o reino do Espirito não só virá como será construído num largo período intra-temporal. Afetará a todos e se constituirá na última etapa da história.

Contra as tendências filosófico-teológicas em vigência no século XII, que abandonavam a perspectiva de encarnação da trindade na história, ao postularem uma arché trinitária impessoal e abstrata, o pensamento de Joaquim de Fiore se ergue soberano reiterando a constante presença da trindade no mundo desde os tempos de sua criação; e, para surpresa de muitos, anuncia uma última e renovadora manifestação da divindade na história. Revigorando e transformando a tradicional lectio historiae, que já caía em desuso e era alvo de duras críticas com o nascer da escolástica, Joaquim Fiore rompe de modo definitivo com uma escatologia imediatista que alimentava o pensamento da Alta Idade Média. Conforme bem sugere Georges Duby, esta expectativa escatológica impera até o momento em que 0 abade cisterciense Joaquim de Fiore dá mais um prazo para o término da aventura humana ao projetar uma terceira idade do mundo. ${ }^{33}$

É necessário observar, por fim, que a visão de história firmada na obra do abade de Fiore não pode simplesmente ser entendida dentro do hiato que a separa de sua concepção de trindade, como muitos especialistas têm hoje observado; menos ainda, pode ser tratada sem que se leve em conta a íntima relação com o seu método concordista, visto que este fornece a chave que permite saber como está esboçado o plano global da história desde seus detalhes mínimos até a sua estrutura mais ampla.

33 DUBY, G. San Bernardo y el arte cisterciense. (El nacimiento del gótico) Trad. castellana de Luiz Muñis. Niadrid: Taurus, 1986, p. 134-35. 